\title{
Confidentiality within physiotherapy: perceptions and attitudes of clinical practitioners
}

Susan Cross and Julius Sim Royal Hospital Haslar, Gosport and Keele University, Keele, Staffordshire

\begin{abstract}
Objectives-This study examined the issue of confidentiality in relation to i) undergraduate curriculum content in physiotherapy, and ii) the awareness, experiences and attitudes of clinical physiotherapists.

Design-Postal survey of universities and focus group interviews with physiotherapists.

Setting - Twenty-five universities in the UK and Ireland and 44 therapists in five hospitals in southern England.

Results-The survey of universities indicated that legal and ethical aspects of confidentiality featured in virtually all preregistration courses that responded.

However, whereas its inclusion was rated as extremely important, the degree of coverage of confidentiality varied considerably between courses. Within the focus groups, 35 informants recollected coverage of confidentiality in their preregistration education, and 12 in postregistration in-service training; in neither case was this coverage in great detail. Informants identified environmental factors and working practices as barriers to preserving confidentiality. Disclosure to others also gave rise to difficulties. Informants were only aware in general terms of the relevant sections of the Chartered Society of Physiotherapy's Rules of Professional Conduct.

Conclusions-Aspects of hospital-based physiotherapy practice were seen to create specific problems in relation to confidentiality. More detailed sources of education and guidance on this issue appear to be required.

(Fournal of Medical Ethics 2000;26:447-453)
\end{abstract}

Keywords: Confidentiality; ethics; physical therapy

\section{Introduction}

Confidentiality has been defined as " $[\mathrm{t}]$ he principle of maintaining the security of information elicited from an individual in the privileged circumstances of a professional relationship". Information need not be derived directly from a patient for it to be confidential, and confidentiality does not depend on an explicit request from the patient, nor on an explicit assurance from the practitioner. ${ }^{2}$ Confidentiality relates only to information that the patient regards (or can reasonably be assumed to regard) as private. ${ }^{3}$ A failure to respect confidential information undermines the autonomy of the individual concerned and, if adverse consequences result, contravenes the principle of non-maleficence.

Barnitt $^{45}$ and Triezenberg ${ }^{6}$ found that confidentiality emerged prominently from their research on ethics with therapists in the UK and USA respectively. Two surveys of members of psychological associations have found confidentiality to be the most frequently nominated area of ethical conflict. ${ }^{78}$ The HIV pandemic has recently given further prominence and urgency to issues of information control, ${ }^{9-11}$ and health care staff have increasingly to deal with confidentiality clauses in their contracts. ${ }^{12}$ The issue of confidentiality is typical of the "everyday" ethical conflicts that face therapists, in contrast to the more dramatic cases on which the ethics of medicine tends to focus. ${ }^{513}$

Although there is a rich theoretical literature on confidentiality, little is known about the knowledge and attitudes of health professionals. This study set out to explore conceptions of confidentiality among physiotherapists working in the UK National Health Service (NHS). Specific objectives were to gather information on:

- The place of confidentiality in the preregistration physiotherapy curriculum

- Physiotherapists' training and education in confidentiality, at both pre- and postregistration levels

- The way in which physiotherapists define confidentiality and relate it to their daily practice

- The ethical difficulties that therapists have encountered in respect of confidentiality in their clinical practice.

\section{Methods}

Information in this study was gained through two approaches. First, a short questionnaire was mailed to university physiotherapy departments to ascertain what is taught on physiotherapy courses in relation to confidentiality and the perceived importance of this material. This was intended to provide background information on confidentiality within the current education of UK physiotherapists. Second, focus group interviews were conducted with practising clinicians in NHS hospitals to gain greater insight into the issue of confidentiality within physiotherapy. A questionnaire was given to the focus group members prior to the interviews, to gather descriptive information on the 
study sample and to ascertain the level and depth of education previously received on this topic.

\section{QUESTIONNAIRE TO UNIVERSITIES}

A postal questionnaire was sent to all universitybased or university-affiliated physiotherapy programmes in the UK and Ireland $(n=29)$. Content validity of the questionnaire was established by submitting it to three experts in the field to obtain comments with respect to its content and scope. Prior to mailing the questionnaire to respondents, the questionnaire was also pretested by sending it to colleagues with expertise in questionnaire design for comment and criticism (the fact that a census of physiotherapy programmes was conducted precluded a pilot within this group).

\section{FOCUS GROUP INTERVIEWS}

A focus group is a group interview, centred on a specific topic and facilitated and coordinated by a moderator, that seeks to generate qualitative data by capitalising on the interaction that occurs within the group setting..$^{14}$ The aim of the focus groups was to elicit the perceptions, feelings, attitudes and everyday experiences of physiotherapists in relation to confidentiality.

A purposive sample of chartered physiotherapists working in the NHS in southern England was selected. An attempt was made to recruit informants of approximately similar professional status so as to create homogeneous groups, which is considered important in encouraging productive and uninhibited discussion. ${ }^{15}$ Following recommendations in the literature, ${ }^{16} 17$ this study worked with groups of eight to ten subjects. Fifty physiotherapists were invited to take part, of whom 44 were subsequently interviewed in five groups in five different hospitals. Potential participants were contacted by post, having been identified to the researchers by a contact person in each hospital. Assurances of anonymity were given, and written consent to participation was sought. A pilot focus group was conducted with eight informants similar to those to be used in the main study.

The groups were moderated by one of the researchers on the basis of a schedule of topics, and were tape-recorded. The schedule covered the following broad topics:

- Informants' training and education in confidentiality

- Confidentiality in the health care environment

- Working practices and confidentiality (including good and bad practices)

- The nature of information (categories of information that are confidential within the therapistpatient relationship)

- Sources of information on confidentiality (policies, procedures, codes of conduct)

- Disclosure of information (those to whom confidential information may be disclosed, and under what circumstances; handling problematic situations).
Prior to the focus group, a questionnaire was given to all participants to gather basic demographic data and to gain information on their experience and education in relation to confidentiality. The interviews, which lasted approximately one hour, were held in an informal, comfortable and private setting, free from interruptions and distractions. By the final focus group, it was felt that "saturation" had been reached, ${ }^{17}$ as by this point the data gathered added little insight to the findings from the previous groups.

\section{DATA ANALYSIS}

The questionnaire data were analysed principally by means of descriptive statistics. The analysis of the transcribed focus group proceedings used the following steps: $:^{15}$

1 Identifying the key areas (identifying the broad topics and ideas that emerged from the data).

2 Unitising the data (identifying specific quotations that express informants' perceptions and feelings, and that can subsequently be used to define categories).

3 Allocating the units (all units identified in the previous step were grouped into homogeneous categories; these categories were not predetermined, but were generated inductively from the data).

4 Negotiating categories (categories were reviewed and joined or subdivided and new categories were created, as appropriate).

5 Identifying themes (the revised categories and supporting units were re-examined and refined and restated as themes).

Step 1 and 3 were completed by one of the researchers and an analyst unconnected with the study, working independently. No major disagreements occurred between the analysts, and minor differences were resolved through discussion. Following analysis of each individual focus group, common themes and categories were identified and noted across groups, and a note was made of their relative prevalence.

\section{Results}

SURVEY OF UNIVERSITIES

Twenty-five universities (86\%) responded to the questionnaire. Of these, $24(96 \%)$ indicated that confidentiality was covered in the preregistration course. The Rules of Professional Conduct of the Chartered Society of Physiotherapy ${ }^{18}$ emerged as the specific issue within confidentiality most often addressed. Other areas commonly nominated were, in descending order of frequency: the issue of disclosure, ethical principles, case studies, research, and record keeping. Seventeen universities $(68 \%$ of responders) indicated the approximate number of hours in the course devoted to the issue of confidentiality: this ranged from one to 30 hours, with a mean of 7.4 hours. In 24 universities (96\%), 
Table 1 Participants in the focus groups. Professional grades are listed in ascending order of seniority; Senior I and above normally indicate a therapist who has specialised in a particular area of clinical practice. An honours degree is generally thought to indicate higher academic achievement than a degree.

\begin{tabular}{lc}
\hline Category & Frequency (\%) \\
\hline Age & $29(66)$ \\
$21-30$ & $8(18)$ \\
$31-40$ & $3(7)$ \\
$41-50$ & $4(9)$ \\
$51-60$ & $18(41)$ \\
Grade & $10(23)$ \\
Junior & $15(34)$ \\
Senior II & $1(2)$ \\
Senior I & $19(43)$ \\
Superintendent & $2(5)$ \\
Qualifications & $23(52)$ \\
diploma & \\
degree & \\
honours degree & \\
\hline
\end{tabular}

the subject was taught by a physiotherapist. This was often in conjunction with other disciplinessuch as lawyers, philosophers and nurses-but in 13 (54\%) cases, physiotherapists alone taught this subject.

Respondents were asked to rate the importance of confidentiality as a subject within the preregistration course on an 11-point scale (0 "not important", 10 "extremely important"), and this yielded a median rating of 10 (interquartile range [IQR] 9-10).

ISSUES EMERGING FROM THE FOCUS GROUPS

Forty-four informants (table 1) were interviewed, in four groups of nine and one group of eight. The topics and issues to emerge from the focus groups will be presented under headings used in the interview schedule. A discussion of the issues raised will follow.

\section{Training and sources of information on} confidentiality

In the questionnaire completed prior to the focus groups, thirty-five $(80 \%)$ informants indicated that confidentiality had been covered in their initial physiotherapy education $(89 \%$ of juniors, $80 \%$ of senior IIs, $69 \%$ of senior Is, and the sole superintendent). The detail in which the topic had been covered, measured on a $0-10$ scale (0 "none at all", 10 "very detailed"), achieved a median rating of five (IQR 3-7). The senior I and superintendent therapists returned a lower median rating (3) than the senior IIs (5.5) and the juniors (5).

Twelve $(27 \%)$ respondents-six $(33 \%)$ of the juniors, six $(40 \%)$ of the senior Is-indicated that confidentiality had been covered in their in-service training since qualifying, and the median level of perceived detail of this training, on the same $0-10$ scale, was five (IQR 3.5-6).

In the focus group interviews, some therapists stated that they did not cover the issue of confidentiality at all within their training. For many others, the topic was not addressed specifically, but was part of wider discussions on other topics, frequently while on fieldwork placements. Often, the subject was addressed in general terms:

"We had a talk on confidentiality, it mainly covered not talking in canteens, not mentioning names and that you can be dismissed if you breach confidentiality."

Many therapists reported heightened awareness of medicolegal issues in health care, but felt that their training had not prepared them adequately to deal with situations involving confidential information.

Most informants were unaware of specific written policies or procedures relating to confidentiality. Some stated that there were written policies regarding solicitors' letters requesting information on patients. Informants were generally aware of a contractual requirement to maintain confidentiality, and mention was made of documents such as the Patient's Charter and the CSP Rules of Professional Conduct. ${ }^{18}$ All informants seemed to be aware that the CSP rules contain a statement on confidentiality, but there was less certainty as to what it precisely entailed. There was no mention of specific legislation to protect confidentiality.

\section{The health care environment}

All the therapists identified certain environmental problems that restricted the extent to which confidentiality could be maintained within physiotherapy departments and hospital wards:

Curtained areas-one therapist commented that "patients sitting in the next cubicle can hear everything".

Lack of facilities-participants identified a lack of private rooms for patient examination, patient "handover", or telephone calls.

Department layout-it was pointed out that the department is often freely accessible and is frequented by a wide variety of staff, patients and others; in addition, there is a lack of separate patient waiting areas, and the telephone may be within earshot of the waiting area.

The nature of group work-three main issues were identified here: i) unintentional disclosure through discussion in the presence of the rest of the group; ii) little or no privacy for patient examination; iii) difficulty in leaving the group to discuss potentially confidential issues.

Time pressures-owing to the shortage of time, patients may have to be discussed in inappropriate places; therapists may also have to take notes home to write them up.

Increased use of computerised notes-staff not involved in the care of the patient may have access to detailed information.

The multidisciplinary team-by its very nature, multidisciplinary working makes patient information available to a wide range of people. 
Working practices

The majority of therapists considered that on the whole physiotherapists were aware of, and respected, confidentiality, but felt that there were numerous areas where physiotherapists fall short of necessary standards, unintentionally in most cases. The following were identified as undesirable practice:

- Discussing or referring to patients in open settings, such as reception areas, corridors and canteens

- Gossiping about patients in staff rooms, lifts, coffee lounges and outside the work setting

- Making and taking telephone calls in earshot of other patients

- Leaving case notes on desks, rather than putting them out of sight

- Conducting patient handovers in inappropriate places

- Inappropriate use of intercom systems

- Unintentional disclosure of information to other patients, for example if a telephone is left off the hook.

\section{The nature of information}

Many therapists stated that because of the amount of time they spend with their patients, they are privy to much detailed and personal information. They also recognised that the relationship between therapist and patient is built on trust and an understanding that confidential information will be protected. One informant remarked: "If the patient thinks I'm going to tell other people then he is not going to tell me things that I need to know for treatment purposes".

Some participants reported that being in possession of so much information created a problem in distinguishing what information should be considered confidential and what information could legitimately be disclosed.

\section{Disclosure of information}

The majority of therapists stated that they were justified in disclosing information to other physiotherapists, on a "need to know" basis, as this was necessary for effective treatment, especially when referring a patient. One participant also commented that "talking about conditions and certain situations is educational-it's a learning experience". There was general agreement that names should only be mentioned when it was necessary to identify a specific patient, such as when referring a patient to a colleague.

Many informants stressed that all health care practitioners are bound by the same obligation of confidentiality, and that this therefore served to safeguard confidential information within a multiprofessional team. One physiotherapist regarded such transfer of information as "just part of continuing care; it's the same care package and you're just one person in that". Informants further indicated that they would take the same view in their dealings with professionals outside the imme- diate health care context, such as social services and teachers.

In other situations, however, there was considerable uncertainty as to when it was appropriate to disclose. Most participants reported having encountered situations where patients had divulged information that could significantly affect their treatment or management and felt that they would disclose such information to appropriate colleagues, particularly if the patient was at risk. The common dilemma reported was that of potential suicide. One informant was clear as to what is appropriate in this situation: "If the patient is at risk and it will help to share that information there is no doubt, someone else needs to know".

However, a few informants felt it was not their prerogative as physiotherapists to disclose information in situations of this kind, and that the patient should make his or her own decision. Indeed, when specifically asked for their view on this issue, all the therapists stated that where patients are able to make their own decisions, they do not involve others in the interchange of personal information, unless requested by the patient to do so. In situations where patients are unable to make their own decisions-elderly confused individuals and head-injured patients were reported as examples-all the therapists would discuss issues with relatives.

Some informants identified situations where information divulged by patients had no bearing on their clinical problem. Here, the common situation was that of illegal actions, such as driving when not permitted to do so. Some therapists were categorical that this did not constitute grounds for disclosure. Others, however, stated that if a patient posed a risk to others they would disclose that information. One therapist specifically argued that "you have a responsibility to others besides the patient". In such situations, some of these therapists reported a conflict between their professional duty to maintain confidentiality and their personal feelings, for example:

"If a patient divulges information of illegal acts, on a personal level I feel the information should be disclosed but, in my position as a health care worker, I'm sworn to secrecy."

Some informants drew a distinction between cases in which the patient him- or herself was at risk, when they would not disclose, and those in which others were at risk, when they would tend to disclose. Other informants, however, took a contrary view and advocated disclosure to protect the patient from risk, but not to protect others.

Two specific cases that arose in this connection were driving without a licence or when intoxicated, and child abuse. In both cases, a number of informants would be prepared to disclose information to the appropriate authority. However, there was disagreement on this issue, and one informant maintained: "Even if a child is at risk it is not our place to disclose the information". For some, the 
possible consequences of this sort of disclosure were very worrisome:

"I just don't know-the trouble is if you get people like social services involved, you get the full weight of the law coming down and what if it's wrong?"

Overall, it was felt that the patient's permission should normally be sought prior to disclosing any information. A minority of therapists were very categorical on this issue and argued that all information about patients was confidential and should not be disclosed under any circumstances. One remarked: "I believe that whatever a patient tells you, it is confidential and you should never disclose it".

If such permission were not forthcoming, however, some therapists would encourage patients to take action themselves, for example to disclose information to the appropriate party on their own initiative. When faced with difficult decisions on disclosure, a number of therapists pointed out that they would use the "hierarchy" for guidance: "I'd go to my senior"; "I'd go to my superintendent", "I'd go to my manager"; "I'd go higher"; "I'd refer back to the GP [general practitioner]". However, there was a feeling among many that specific permission was not required when dealing with other professionals who also have a duty to respect confidentiality.

\section{Discussion}

It is acknowledged that awareness of legal and ethical issues assists considerably in understanding the nature and implications of professional responsibilities. ${ }^{19} 20$ All the responding universities considered the inclusion of confidentiality within undergraduate courses to be very importan (though this question may well have been subject to a social desirability bias). However, the time allocated to this topic and therapists' perception of the detail in which it had been covered were variable. Moreover, $20 \%$ of the focus group participants, and approximately $30 \%$ of the more senior informants, did not recollect any coverage of confidentiality in their preregistration education. Even fewer had covered confidentiality in their postregistration in-service education.

The reported level of detail, for both preregistration and postregistration education, was not very high. The more junior informants, who can be assumed to have received their professional education more recently, reported a slightly higher leve of detail than their more senior colleagues did. This suggests a greater accent on this topic in professional education programmes in the recent past. None the less, many therapists indicated during the focus groups that their training had not prepared them adequately to deal with the many problems they face in working practice.

Many of the issues raised in the focus groups relate directly to the particular working circumstances of hospital-based physiotherapists. Rather than working within a fixed, designated office, these therapists are liable to move frequently from the department to the ward, or from ward to ward, making contact with other professionals while "on the move". In such semipublic places, there are numerous opportunities for what Siegler refers to as "the wanton, often inadvertent, but avoidable exchanges of confidential information that occur frequently in hospital rooms, elevators, cafeterias, doctors' offices, and at cocktail parties" ${ }^{21}$ Elevator trips in particular have been shown to be prone to indiscreet communication on the part of health professionals. ${ }^{22}$ This situation was also identified as problematic by an occupational therapist in Barnitt's study, who commented:

"The staff gossiped about the patients to each other, other patients and their relatives, and to any visitors within earshot. I minded more because the information they gossiped about often led to patients being labelled as difficult". ${ }^{5}$

The issue of trust within the therapeutic relationship emerged strongly from the data, and is a prominent one in the literature on confidentiality. ${ }^{211}{ }^{13-27}$ Unless patients are confident that the information they disclose will be treated as confidential, they may be reluctant to reveal certain details of their medical or personal history, or even fail to seek professional help in the first place. ${ }^{26}$ There are important implications here for the effective discharge of clinical practice in physiotherapy.

Many therapists operated an informal "need to know" policy when dealing with confidential information. This is often seen as an appropriate criterion when deciding on whether to disclose, ${ }^{28} 29$ and is widely reflected in professional codes of ethics. ${ }^{20}{ }^{30-32}$ Informants were generally clear that the passage of information between professionals involved in the patient's care was legitimate, and was an exception to, rather than a breach of, confidentiality.

It was clear that a number of informants had identified situations that give rise to serious conflicts of duties in respect of confidentiality. Some of the dilemmas faced by therapists can be acute, particularly in relation to potential suicide by patients. This issue has emerged elsewhere in the therapy literature. A therapist interviewed by Barnitt commented:

"A patient told me a piece of information as a secret which was about her wish to die. I worried about it for weeks and I know I would feel awful if she killed herself and awful if I betrayed her trust and told anyone".

Physiotherapists may find themselves pulled in opposite directions by their perceived duties to the patient concerned, other patients, and society at large. Although duties to the patient in whose care the therapist is engaged may seem paramount in most cases, this may not be the case when there is the potential for serious harm to others. Here, the therapist may feel that the duty to protect others outweighs duties to the patient. 


\section{Public interest}

Whereas some therapists were clear on their respective duties to the patient and to others outside the patient/therapist relationship, others were unclear. There was much more uncertainty and debate during the interviews on disclosure of information in the public interest and outside the health care arena than there was when the question of disclosure related to the patient's own interests. This may suggest that decision making in physiotherapy is perceived to be more straightforward when the patient's welfare is at stake. The fact that a number of therapists in the study felt that confidentiality was an absolute duty further supports this interpretation.

Informants made little reference to the issue of confidentiality in relation to information not directly related to the patient-for example, "whistleblowing". ${ }^{12}{ }^{33}$ It may be that informants in the current study interpreted the issue of confidentiality in a rather narrower sense, principally in respect of patient information. Although informants made reference to the CSP Rules of Professional Conduct ${ }^{18}$ this tended to be in fairly general terms. In particular, none of the participants in the focus groups appeared to be aware of the specific guidelines set out in the rules that deal with several of the conflicts that were debated at length during the interviews. None the less, informants often identified for themselves many of the issues discussed in the rules.

Overall, the physiotherapists in this study exhibited a variety of standpoints on the issue of confidentiality. Whereas some were absolute in their views, others expressed considerable uncertainty. As is frequently the case on ethical matters, a clear moral consensus did not emerge.

\section{Conclusion}

The findings from this study, although not necessarily generalisable to other physiotherapists either within or outside the UK, raise some important issues for professional education and the maintenance of professional ethics within clinical practice.

Many factors were identified by physiotherapists that, in their view, influenced the extent to which confidentiality could be maintained, including environmental problems and the system of working practice. This suggests that hospitals, and physiotherapy departments in particular, could be made more conducive to confidentiality.

This study indicates that confidentiality is a complex and potentially problematic issue for physiotherapists, and one for which they feel ill equipped. There was a general acceptance that certain common breaches of confidentiality are unjustified (such as indiscreet discussions in public places). In other situations, however, genuine ethical dilemmas and situations of divided loyalties were identified, and informants had opposing views as to the appropriate action to take. There is scope for further guidance here. Greater promulgation of the CSP rules may prevent unintentional but unjustified breaches of confidentiality. Such clearly acknowledged ethical obligations might thereby assume the same status as other accepted professional "dos and don'ts", such as treatment contraindications. In respect of genuine dilemmas-with which codes of ethics are of limited help-a greater degree of critical debate and education, at both pre- and postregistration level, would seem appropriate.

\section{Acknowledgements}

We wish to thank Rosemary Barnitt for helpful advice on the conduct of this study and Liz Stannard for assistance with analysis of the focus group transcripts.

Susan Cross, BSc, Msc, is Patient Relations Manager, Royal Hospital Haslar, Gosport, Hampshire and Fulius Sim, BA, MSc, PhD, is Professor in the Department of Physiotherapy Studies, Keele University, Keele, Staffordshire ST5 5BG, UK (author for correspondence).

\section{References}

1 Reid DD. Confidentiality. In: Duncan AS, Dunstan GR, Welbourn RB, eds. Dictionary of medical ethics [2nd ed]. London: Darton, Longman \& Todd, 1981.

2 Sim J. Client confidentiality: ethical issues in occupational therapy. British fournal of Occupational Therapy 1996;59:56-61. 3 Gillon R. Confidentiality. British Medical fournal 1985;291: 1634-6.

4 Barnitt R. What gives you sleepless nights? Ethical practice in occupational therapy. British fournal of Occupational Therapy 1993;56:207-12.

5 Barnitt R. Ethical dilemmas in occupational therapy and physical therapy: a survey of practitioners in the UK National Health Service. Fournal of Medical Ethics 1998;24:193-9.

6 Triezenberg HL. The identification of ethical issues in physical therapy practice. Physical Therapy 1996;76:1097-106

7 therapy practice. Physical Therapy 1996;76:1097-106. ety. The Psychologist 1995;8:448-51.

8 Pope KS, Vetter VA. Ethical dilemmas encountered by members of the American Psychological Association-a national survey. American Psychologist 1992;47:397-411.

9 Boyd KM. HIV infection and AIDS: the ethics of medical confidentiality. Fournal of Medical Ethics 1992;18:173-9.

10 Allmark P. HIV and the boundaries of confidentiality. fournal of Advanced Nursing 1995;21:158-63.

11 Sim J. HIV status and confidentiality. Physiotherapy 1997;83: 90-6.

12 Hunt G. Whistleblowing in the health service: accountability, law and professional practice. London: Edward Arnold, 1995.

$13 \mathrm{Sim}$ J. Ethical decision making in therapy practice. Oxford: Butterworth-Heinemann, 1997.

$14 \mathrm{Sim} \mathrm{J}$, Snell J. Focus groups in physiotherapy evaluation and research. Physiotherapy 1996;82:189-98

15 Vaughn S, Schumm JS, Sinagub J. Focus group interviews in education and psychology. Thousand Oaks: Sage Publications, 1996. 6 Basch CE. Focus group interview: an underutilized research technique for improving theory and practice in health technique for improving theory and practice in
education. Health Education Quarterly 1987;14:411-48.

17 Krueger RA. Focus groups: a practical guide for applied research [2nd ed]. Thousand Oaks: Sage Publications, 1994.

18 Chartered Society of Physiotherapy. Rules of professional conduct. London: Chartered Society of Physiotherapy, 1996.

19 Parkes R. The duty of confidence. British Medical fournal 1982;285:1442-3.

20 Young AP. Legal problems in nursing practice [2nd ed]. London: Harper \& Row, 1989

21 Siegler M. Confidentiality in medicine-a decrepit concept. In Mappes TA, Zembaty JS, eds. Biomedical ethics [3rd ed]. New York: McGraw-Hill, 1991 .

22 Ubel PA, Zell MM, Miller DJ, Fischer GS, Peters-Stefani D, Arnold RM. Elevator talk: observational study of inappropriate comments in a public space. American fournal of Medicine 1995;99:190-4.

23 Thompson IE. The nature of confidentiality. Fournal of Medical Ethics 1979;5:57-64. 
24 Bok S. Secrets: on the ethics of concealment and revelation. Oxford: Oxford University Press, 1984

25 Koehn D. The ground of professional ethics. London: Routledge, 1994.

26 Kottow MH. Stringent and predictable medical confidentiality n: Gillon R, Lloyd A, eds. Principles of health care ethics. Chichester: John Wiley, 1994

27 Bailey DM, Schwartzberg SL. Ethical and legal dilemmas in occupational therapy. Philadelphia: W B Saunders, 1995.

28 Walters L. Ethical aspects of medical confidentiality. In: Beauchamp TL, Walters L, eds. Contemporary issues in bioethics. Encino: Dickenson Publishing, 1978.
29 Brody H. The physician/patient relationship. In: Veatch RM, ed. Medical ethics. Boston: Jones and Bartlett, 1989.

30 British Association of Occupational Therapists. Code of professional conduct. London: British Association of Occupational Therapists, 1990.

31 American Physical Therapy Association. Code of ethics. Alexandria: American Physical Therapy Association, 1991.

32 British Medical Association. Medical ethics today: its practice and philosophy. London: British Medical Association, 1993.

33 Hewison A, Sim J. Codes of ethics and interprofessional working. Fournal of Interprofessional Care 1998;12:309-21. 